\title{
A cross-sectional study of fall injuries in senior people attending emergency ward in BPKIHS, a tertiary level hospital, Dharan, eastern region of Nepal
}

\author{
BK Rai, R Chaudhari, A Yadav, B Rai \\ Department of General Practice and Emergency Medicine
}

\begin{abstract}
Background: The Senior or elderly population is rapidly growing in Nepal. They sustain injuries fall frequently which is mostly unintentional and occurs either inside or outside of house. The cost of treatment is high. The most effective fall prevention strategies are multifactorial interventions targeting identified risk factors, exercises for muscle strengthening combined with balance training and withdrawal of psychotropic medication. Objective: To study the pattern and associated rule factors of fall injuries among elderly patients from frequenting in the emergency. Method: It is an observational cross sectional study of fall in senior people presenting in emergency ward using a semi-structured questionnaire. Result: Male and female subjects were $76(54.3 \%)$ and 64 (45.7\%) respectively. Among 140 patients, $115(82.1 \%)$ were living with families and 25 (17.9\%) were living alone. Fifty six (40\%) patients sustained injuries in early morning, fifty-two (37.1\%) in late evening and thirty two (22.9\%) in the afternoon. Seventy-three percent subjects fell outside and $26.40 \%$ fell inside house. Sixty-five (53.6\%) patients were suffering from chronic diseases. Fifty-seven (40.7\%) patients were suffering from visual impairment. Fourty-seven (33.6\%) patients had multiple joints problem, 20\% subjects were anaemic. Hypoglyceaemia was present in fifteen (10.7\%) subject. Eighteen (12.9\%) subjects had a history of fall in past. Eighteen (12.9\%) subject had head injury. Twelve (8.6\%) subjects had chest injury. Three (2.1\%) subjects had abdominal injury and 24 (17.1\%) spinal injury. Seventy-three (52.1\%) subjects had fracture, $30(21.4 \%)$ had soft tissue injury, 48 (34.3\%) external injury and 11 (7.9\%) eye most common injury found in elderly patients in this set up. Mosy of the fall injury injuries. Of all 82 (30.7\%) patients were admitted in hospital. Conclusion: Fracture of bone was the occurred outside home. Most of the patients required admission in the hospital for treatment.
\end{abstract}

Keywords: Fall, high cost effective, morbidity, senior people

\author{
Address for correspondence \\ Bijendra Kumar Rai \\ Department of GP and EM \\ B.P. Koirala Institute of Health Sciences, Dharan \\ E-mail: bijen001@gmail.com
}




\section{Introduction}

The senior or elderly people are rapidly growing in the Nepal. According to National Population Census 2011, the total population of Nepal found to be 26620809 and percentage of senior citizen is 4.20. In Nepal people over 60 years old are called old or senior people. The WHO defines senior citizens as 60 years and over. ${ }^{1}$

The ageing process is contributory factor of fall in elderly people. The age associated deterioration occurs in vision, hearing, muscles bulk, joints, lungs, heart, kidneys, brain and immune system. There is always problem in mastication, bladder and bowel function. There is decreased in bone density and impairment in cognitive function. These are major risks factors for fall. ${ }^{2}$

About $30 \%$ of people over the age of 60 may have experiences at least one fall per year. Most of the cases of fall need hospital admissions for about $14 \%$ of emergency admission and 4\% all hospital admission for trauma, loss of independence and injury deaths. $^{3,4}$

The mnemonic 'I HATE FALLING' for physical findings in elderly people would be one of the cause of fall in elderly people. $\mathrm{I}=$ inflammation of joint $\mathrm{s}$ (or deformity), $\mathrm{H}=$ hypotension (orthostatic blood pressure changes), $\mathrm{A}=$ auditory and visual abnormalities., $\mathrm{T}=$ tremor (Parkinson's disease or other causes of tremor), $\mathrm{E}=$ equilibrium (balance) problem, $F=$ foot problems, $\mathrm{A}=$ arrhythmia, heart block or valvular heart diseases, $L=$ leg-length discrepancy, $L=$ lack of conditioning (generalized weakness), $\mathrm{I}=$ illness, $\mathrm{N}=$ nutrition (poor, weight loss), $\mathrm{G}=$ gait disturbance. $^{5}$

The causes of fall are usually unintentional and unintentional injuries are the fifth leading cause of death in older adults after cardiovascular disease, cancer, stroke and pulmonary disorders. ${ }^{5}$ Oliver $D$ et al found the need for frequent toileting and visual impairment are risk factors for fall. ${ }^{7}$

The use of polypharmacy (taking more than four medications daily) are also risk factors for falls. ${ }^{8,9}$ Fall related injuries cause serious physical disablility and mental effects to the senior people and require long time hospital admission. ${ }^{10}$ Age-associated impairments of vision, hearing and memory also tend to increase the number of trips and stumbles. ${ }^{11}$ The next major reported cause of falls is dizziness which is an extremely common symptom among older persons. However, it is a non-specific symptom and may reflect problems as diverse as cardiovascular disorders, hyperventilation, orthostatic hypotension, drug side-effect, anxiety and depression. The consequences of fall-related injuries can be both physically and financially costly. $^{12}$ 
In elderly people, fall increases the risk of hip fracture three to five times, and when such a fall causes an impact to the greater trochanter of the proximal femur, hip fracture risk is raised about 30 times. $^{13}$ It has been found in a recent fracture, the risk of another fall is increased, resulting in subsequent fracture. ${ }^{14}$

The chronic pain and moderate or vigorous physical activities could enhance falls selfefficacy. ${ }^{15,16}$ The elderly people with fractures lower limbs other lesions and the fear of falling may result in auto-restrictions in daily living activities, producing immobility, loss of self-esteem and social isolation. Therefore the interventions for the prevention and treatment of the falling fear in the elderly are very important to assure a good quality of life. ${ }^{17}$ The fall in senior people is also common in developed countries with high cost of treatment. $^{18}$

Falls, particularly falls at home (which in themselves may be trivial, mere slips to the floor), are the most common accidents of the elderly with the highest rate of accidental deaths. ${ }^{19}$ Their cost to individual patients and to society in terms of incidence, morbidity and mortality is enormous. In the very simple way the causes of falls are classified into extrinsic and intrinsic factors. The latter include disorders of many organ systems, especially those resulting from neurological and cardiovascular diseases. ${ }^{20}$
The present study aimed to find out the pattern and associated risk factors of fall injuries among elderly patients presenting in the emergency.

\section{Methods}

It was a cross sectional study. The subjects included in this study were senior people aged 60 years and above who were admitted in the Emergency Ward in BPKIHS with history of fall. The study was conducted over a period of one year from $1^{\text {st }}$ July to $30^{\text {th }}$ June 2013. The total sample size was 140 .

As per rule, ethical clearance was obtained from institutional ethical research committee of BPKIHS. A semi- structured questionnaires sheet was filled-up by investigators themselves in the emergency ward. The details of the study was explained to every patient and those patient who agreed to participate were included. The informed consent was taken from patient him/herself or patient's relative or close person.

The questionnaire comprised items concerning circumstances of fall, causes of the fall, consequences of the fall, sociodemographic characteristics and healthrelated characteristics. Finally data was analyzed by using the SPSS (Software Package of Social Sciences)-20. The various methods of graphical presentation were used to describe demographic and other parameters. 


\section{Results}

This research study was conducted in $1^{\text {st }}$ June 2012 to $30^{\text {th }}$ July 2013. The study result showed male and female subjects were $76(54.3 \%)$ and $64(45.7 \%)$ respectively. The age ranged from 60 to 92 years. The mean of the age 70.3 . The Male : female ratio was 19:16.

Table 1: Age

\begin{tabular}{|l|l|l|}
\hline Age in years & Frequency & Percent \\
\hline $60-64$ & 22 & 15.7 \\
\hline $65-69$ & 43 & 30.7 \\
\hline $70-74$ & 39 & 27.9 \\
\hline $75-79$ & 21 & 15.0 \\
\hline $80+$ & 15 & 10.7 \\
\hline Total & 140 & 100.0 \\
\hline
\end{tabular}

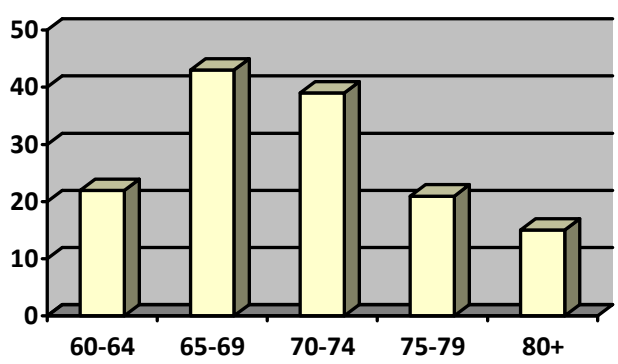

The maximum number of patients came from Sunsari district 44 (31.4\%) followed by Dhankuta 15 (16.7\%), llam 10 (7.1\%), Morang 10 (7.1\%) and Saptari 9 (6.4\%). The least numbers of patients came from
Pachthar 1 (0.7\%) and Rajbiraj 1 (0.7\%). Table 2

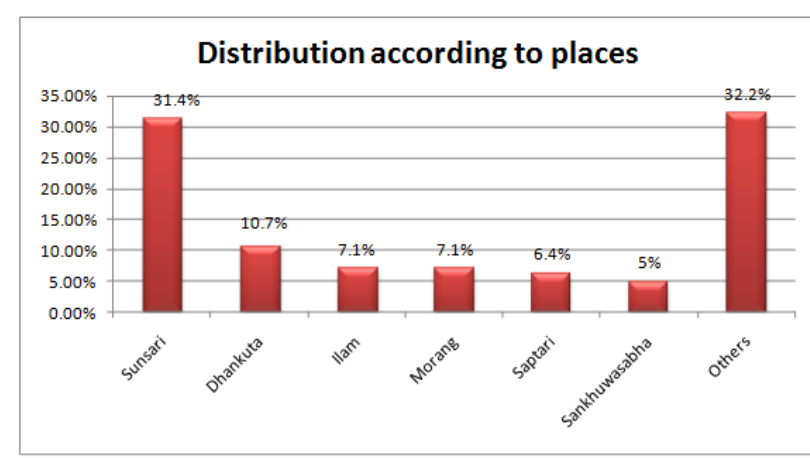

Among 140 patients, 25 lived alone whereas 115 patients lived with family. 56 patients were dependent on others for daily activities whereas 84 were self dependent.

Table 2: Time of fall

\begin{tabular}{|l|c|c|}
\hline & Frequency & Percent \\
\hline Morning & 56 & 40.0 \\
\hline Afternoon & 32 & 22.9 \\
\hline Night & 52 & 37.1 \\
\hline Total & 140 & 100.0 \\
\hline
\end{tabular}

The table showing the percentage of time of fall.

Table 3: Inside the house (place)

\begin{tabular}{|l|l|l|}
\hline & Frequency & Percent \\
\hline Toilet & 15 & 10.7 \\
\hline Bedroom & 6 & 4.3 \\
\hline Kitchen & 9 & 6.4 \\
\hline Living room & 2 & 1.4 \\
\hline Stairs & 5 & 3.6 \\
\hline Fall outside home & 103 & 73.6 \\
\hline
\end{tabular}




\begin{tabular}{|l|l|l|}
\hline Total & 140 & 100.0 \\
\hline
\end{tabular}

Table 4: Place of fall (site-outside)

\begin{tabular}{|l|l|l|}
\hline & Frequency & Percent \\
\hline Toilet & 31 & 22.1 \\
\hline Garden & 33 & 23.6 \\
\hline Road & 30 & 21.4 \\
\hline Others & 9 & 6.4 \\
\hline Fall inside home & 37 & 26.4 \\
\hline Total & 140 & 100.0 \\
\hline
\end{tabular}

Table 5: Visual impairment $(n=140)$

\begin{tabular}{|l|l|l|}
\hline S.N. & Conditions & Present (\%) \\
\hline 1. & Visual impairment & $57(40.7 \%)$ \\
\hline 2. & Joint problem & $47(33.6 \%)$ \\
\hline 3. & Impaired activity & $51(36.4 \%)$ \\
\hline 4. & Chronic disease & $65(46.4 \%)$ \\
\hline 5. & Past h/o fall & $18(12.9 \%)$ \\
\hline 6. & Head injury & $18(12.9 \%)$ \\
\hline 7. & Chest trauma & $12(8.6 \%)$ \\
\hline 8. & Abdominal trauma & $3(2.1 \%)$ \\
\hline 9. & Spinal trauma & $24(17.1 \%)$ \\
\hline 10. & Anemia & $28(20 \%)$ \\
\hline 11. & Fracture & $73(52.1 \%)$ \\
\hline 12. & Pelvic fracture & $16(11.4 \%)$ \\
\hline 13. & Fracture site & $140(100 \%)$ \\
\hline 14. & Eye trauma & $11(7.9 \%)$ \\
\hline 15. & Blood sugar & $140(100 \%)$ \\
\hline 16. & Soft tissue injury & $30(21.4 \%)$ \\
\hline 17. & Other external injury & $48(34.3 \%)$ \\
\hline & & \\
\hline
\end{tabular}

Table 6: Outcome

\begin{tabular}{|l|c|c|}
\hline & Frequency & Percent \\
\hline Admitted & 82 & 58.6 \\
\hline Expired & 2 & 1.4 \\
\hline Discharged & 38 & 27.1 \\
\hline DOPR & 5 & 3.6 \\
\hline LAMA & 5 & 3.6 \\
\hline Referred & 8 & 5.7 \\
\hline Total & 140 & 100.0 \\
\hline
\end{tabular}

\section{Discussion}

Falls in the elderly constitute a major problem confronting physicians. The maximum number of fall found in patients age group 60 to 65 which accounts $43(30.7 \%)$ in this study was comparable to the study done by Kanis JA, Oden A et al in 2007 which also showed similar characteristics.

According to the present study eighty-four $(60 \%)$ patients were able to preformed their daily activities by themselves whereas 56 (56\%) could not perform daily activities so they always need for formal help. This can be due to weakness as it is also one of the major percipating factors for falls, which was well supported by a large longitudinal study done where $10 \%$ needed assistance to walk, $20 \%$ unable to climb stairs without help and $40 \%$ unable to walkhalf a mile.

The result of this study showed the number of patients with accidental fall 56 (40\%) happened in early morning. 52 (37.1\%) in late evening and 32 (22.9\%) in afternoon which 
was also similar to the earlier studies mentioning numbers of fall in elderly people is more common in morning and evening whereas less common in afternoon.

Out of 140 patients 37 fell inside and 103 outside house respectively. Among them major patients fell in toilet room 15 (10.7\%) and in bedroom 6 (4.3\%). This showed the commonest places to be toilet and bedroom and it was quiet similar to the result found in previous study done by Stephen R. According to various literature review these are the extrinsic factors of fall in senior citizens.

Out of 140 patients, sixty-five (53.6\%) were suffering from chronic diseases of different types like hypertension, diabetic mellitus, chronic obstructive airways disease, parkinsonism, prostatic enlargement, osteoarthritis, visual impairment and others. Those chronic conditions were found to be associated alone or with other chronic conditions.those all chronic conditions were found to be the causative factors similar as shown in various other studies done time by time. The simple visual acuity screening in a general practice setting and appropriate referral for visually impaired patients may be a simple cost effective way to fall and subsequent fracture prevention in the elderly. Fourty-seven (33.6\%) patients were getting multiple joints problem, twenty eight (20\%) subjects were anaemic and they felt because of dizziness which was due to severe anaemia. Fifteen (10.7\%) subjects found fall because of hypoglycemia. In previous studies also showed anaemia and hypoglycemia frequently gave rise to fall in elderly subjects. In this study 18 (12.9\%) subjects had a history of fall in past.

Between 30 and 40 percent of communitydwelling elderly people more than 65 years fall each year. Most falls have multiple causes. The most effective fall prevention strategies are multifactorial interventions targeting identified risk factors, exercises for muscle strengthening combined with balance training and withdrawal of psychotropic medication are useful. ${ }^{21}$ The World Health Organization is devising a new model to calculate absolute fracture risk. The model combines, age specifically, six clinical risk factors (previous fracture, glucocorticoid use, family history of fracture, current cigarette smoking, excessive alcohol consumption, and rheumatoid arthritis) with bone mineral density to estimate the 10 year probability of hip and other fractures. ${ }^{22}$

According to this study the major complications of fall were fracture which were $73(52.1 \%), 24(17.1 \%)$ subjects were spinal injury and 18 (12.9\%) subject had head injury. Among the fractures, lower limb fracture were countered $31(22.1 \%)$ to be the most followed 18 (12.4\%) of upper lower limb fracture and $16(11.4 \%)$ of pelvic fracture. This result showed the lower limb fracture is 
common in elderly people which is similar to the research study done by Shobha Rao (July 2005).

As other study this study study also showed the majority of the fall patients were admitted in the hospitals. This study also showed that among 140 patients of fall, 82 (30.7\%) admitted in hospital, 38 (27.1\%) discharged after emergency management, 8 (5.7\%) patients referred to other center, 5 (3.6\%) patients were discharged on request, 5 (3.6\%) left against medical advice and 2 $(1.4 \%)$ dead during emergency treatment.

\section{Conclusion}

The number of elderly people is growing fast and chances of fall are very high due to intrinsic and extrinsic factors and treatment is high cost effective. Fracture of bone was the most common injury formed in elderly patients in this set up. Most of the fall injury occurred outside home. Most of the patients required admission in the hospital for treatment.

\section{References}

1. Countries of the world. World fact book.

http://www.theodora.com/wfbcurrent/n epal/nepal_people.html 2011 Country Ranks, by Rank (Accessed on July 2013)
2. Murtagh John AM, Murtage General Practice, $6^{\text {th }}$ Edition, chapter 8, page no 56, McGraw-Hill Australia Pty Ltd publishers, 2012.

3. Hausdorff JM, Rios DA, Edelber HK. Gait variability and fall risk in community-living older adults: Archives of Physical Medicine and Rehabilitation. 2001;82(8):1050-6.

4. Close J., Ellis M., Hooper R, Glucksman E, Jackson S, Swift C. et.al. Prevention of Falls in the Elderly Trial (PROFET): a randomised controlled trial. Lancet 1999;353:93-7.

5. Peterson LE, Bazenore AW, Philips $\mathrm{RL}$ Jr, Teevan B, Dodoo MS, Xierali I, Petterson SM. Family Physicians' Present and Future in Caring for older Patients. Am Fam Physician. 2009; 80(10):1072.

6. Hornbrook MC, Stevens VJ, Wingfield DJ, Hollis JF, Greenlick MR, Ory MG et.al. Prevention falls among community-dwelling older persons. The Gerontologist 1994; 34(1):16-23.

7. Oliver D, Britton M, Seed $P$, Martin F.C., Hopper AH et.al. Development and evaluation of evidence based risk assessment tool (STRATIFY) to predict which elderly inpatients will fall: Case control and cohort studies. BMJ 1997:315: 1049-1053. 
8. Lord SR, Menz HB, Sherrington C. Age and ageing. Oxford Journal of Medicine. 2006;135: 5-59

9. Gribbin J, Hubbard R, Gladman J, Smith C, Lewis $S$ et al. Drugs Ageing.2011; 28(11):895-902.

10. Bell AJ, Talbot- Stern JK, Hennessy A. The Characteristics and outcome s of older patients presenting to the emergency department after a fall. Medical journal of Australia 200;173(4):176-7

11. Stevens JA., Ryan G, Kresnow M et.al. Fatalities and injuries from falls among older adults. The United State, 1993-2003 and 2001-2005. MMWR 2006a; 55(45).

12. George F. Fuller. Col, MC USA. Am Fam Physician. Falls in the elderly. $2000 ; 61(7): 2159-2168$.

13. Sloan JP. Mobility failure. In: Protocols in primary care geriatrics. New York: Springer, 1997:33-8.

14. Robinovitch SN, Inkster L, Maurer J, Warnick B. Strategies for avoiding hip impact during sideways falls. J Bone Miner Res2003;18:1267-73.

15 Vellas BJ, Wayne SJ, Romero LJ, Baumgartner RN, Garry PJ et.al. Fear of falling and restriction of mobility in elderly fallers. Age and Aging 1997; 26:189-193.
16. Besdine $\mathrm{R}$, Boult $\mathrm{C}$, Brangman $\mathrm{S}$, Coleman EA, Fried LP, Gerety $M$ et al. Caring for older American. J. Am. Geriatric Society. 2005: 53(6 Suppl): S245-56.

17. Ronen N, Zasshi L. Factors affecting falls self-efficacy of home-bound elderly people. 2010; 47(4):323-8.

18. Gomes GJ, De Cardenas J. The fear of falling in elderly. Acta Med Port. ...; 22(1):83-8

19. Rao S. Prevention of falls in older patients Am Fam Physician.2005; 72(1):81-8

20. Wendelboe AM, Landen MG. Increased fall-related mortality rates in New Mexico. Public Health Rep. 2011;126(6):861-7

21. Handfield R. Falls in the elderly: a practical approach. Canadian Fam Physician. 1989; 35:637-42.

22. Kanis JA, Oden A, Johnell $O$, Johansson $\mathrm{H}$, Brown J, Cooper C et.al. The use of clinical risk factors enhances the performance of BMD in the prediction of hip and osteoporotic fractures in men and women. Osteoporos Int 2007;18:1033-46.

23. Whitney JC, Lord SR, Close JC. Streamlining assessment and intervention in a falls clinic using the timed up and go test and physiological 
profile assessments. Age Ageing 2005;34:567-71.

24. Ganz DA, Bao Yeran, Shekelle Y, Rubenstein LZ et.al. Will my patient fall? JAMA 2007;297:77-86.
25. Nikolaus T, Bach M. Preventing falls in community-dwelling frail older people using a home inervention team (HIT): results from the randomized falls-HIT trial. J Am Geriatr Soc2003;51:300-5. 